\title{
KABONG KAENG: TIPOLOGI BARU HUNIAN EKOLOGIS SUKU ASMAT
}

\author{
Stenlie Dharma Putra ${ }^{1)}$, Agustinus Sutanto ${ }^{2)}$ \\ Program Studi S1 Arsitektur, Fakultas Teknik, Universitas Tarumanagara, dpstenlie@gmail.com \\ Program Studi S1 Arsitektur, Fakultas Teknik, Universitas Tarumanagara, berpikirteoripraksis@gmail.com
}

Masuk: 03-07-2021, revisi: 14-08-2021, diterima untuk diterbitkan: 23-10-2021

\begin{abstract}
Abstrak
Perubahan iklim merupakan fenomena global yang belakangan ini menjadi perhatian bersama, dimana berdampak terhadap peningkatan suhu udara. Pegunungan Jayawijaya yang dikenal dengan salju abadinya menjadi berubah dan berdampak terhadap peningkatan kelembaban udara drastis di kawasan tersebut. Fenomena unik di Papua, khususnya Suku Asmat yang kaya dengan hasil alamnya namun disatu sisi mengalami krisis air bersih. Banyak penyakit yang diakibatkan oleh kondisi air yang buruk, karena sebagian masyarakat menggunakan air sungai tanpa diolah terlebih dahulu. Masalah krisis air menjadi permasalahan pokok karena Suku Asmat sangat bergantung dengan alam, mulai dari kebutuhan pangan, MCK, hingga tradisi dan keseniannya. Jika alam semakin rusak, bagaimana cara Suku Asmat bertahan hidup dan beradaptasi kedepannya? Pendekatan arsitektur yang dilakukan adalah metode tipologi, dimana menganalisis karakteristik kehidupan Suku Asmat, untuk kemudian diterapkan terhadap proyek. Selain mengatasi permasalahan yang ada, proyek ini juga mengangkat cara hidup Suku Asmat yang erat dengan kesenian pahat dan tradisi di alam nenek moyangnya. Melalui berbagai riset, bahwa memungkinkan untuk memanfaatkan kelembaban dan air hujan sebagai sumber air di masa depan. Dari sisi energi, dikatakan sustainable karena curah hujan tinggi di alam Papua. Dampaknya terhadap ekosistem tidak negatif karena berasal dari alam. Sumber air ini dapat dimanfaatkan Suku Asmat untuk beradaptasi cara hidup dan memanfaatkan sumber air tersebut untuk keberlanjutan dan pelestarian peradaban mereka di masa mendatang.
\end{abstract}

Kata Kunci: Arsitektur Ekohidrologi; Hunian; Krisis Air Bersih; Suku Asmat; Tipologi

\begin{abstract}
Climate change is a global phenomenon that has recently become a common concern, which has an impact on increasing air temperatures. The Jayawijaya Mountains, which are known for their eternal snow, have changed and have an impact on the drastic increase in humidity in the area. This unique phenomenon in Papua, especially the Asmat tribe, which is rich in natural products, but on the one hand is experiencing a clean water crisis. Many diseases are caused by poor water conditions, because some people use river water without being treated first. The problem of water crisis is a major problem because the Asmat tribe is very dependent on nature, starting from their food needs, toilets, to their traditions and arts. If nature is getting more and more damaged, how will the Asmat tribe survive and adapt in the future? The architectural approach taken is the typology method, which analyzes the characteristics of the life of the Asmat Tribe, to then be applied to the project. In addition to overcoming existing problems, this project also raises the way of life of the Asmat Tribe which is closely related to sculpture and traditions in the realm of their ancestors. Through various research, it is possible to use humidity and rainwater as a source of water in the future. In terms of energy, it is said to be sustainable because of the high rainfall in Papua. The impact on the ecosystem is not negative because it comes from nature. This water source can be used by the Asmat tribe to adapt to their way of life and utilize this water source for the sustainability and preservation of their civilization in the future.
\end{abstract}

Keywords: Ecohydrology Architecture; Dwelling; Clean Water Crisis; Asmat Tribe; Typology 


\section{PENDAHULUAN}

\section{Latar Belakang}

Sekitar sepertiga penduduk di dunia hidup dalam keadaan "krisis ketersediaan air yang tinggi", menurut penelitian dari World Resources Institute (WRI), yaitu sebuah lembaga riset yang terletak di Washington DC. Kurangnya air bersih menyebabkan berbagai penyakit yang berbahaya bagi kesehatan. Kedepannya masalah ini diyakini akan semakin besar jika manusia tidak dapat memperbaiki masalah ekosistem yang ada saat ini. (WRI, 2019)

"di tahun 2040 Jawa akan 'kehabisan air' dan ratusan juta orang terancam bencana yang 'tak pernahterbayangkan" dan "dalam 5 tahun mendatang Jayapura akan terancam krisis air bersih".

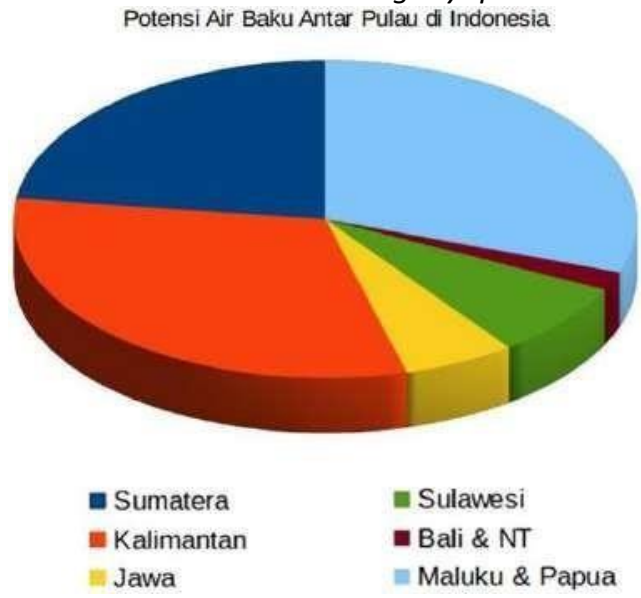

Gambar 1. Diagram Potensi Air Bersih Sumber : www.google.com, 2014

Mantan Direktur Jenderal Cipta Karya Kementerian Pekerjaan Umum, Ir. Budi Yuwono, dalam Indonesia Water Investment Roadmap 2011-2014 menyatakan bahwa hanya 47,71\% dari total penduduk Indonesia yang mendapatkan akses terhadap sumber air bersih. Padahal, berdasarkan Buku Tahunan Sumber Daya Air Kementerian Pekerjaan Umum tahun 2010-2011, menyatakan cadangan air Indonesia merupakan yang terbesar ke-5 dunia yaitu sebesar 3.221 miliar meter kubik per tahun, dan hanya 175,1 miliar meter kubik per tahun atau sekitar 25,33\% dari kapasitas yang sudah dimanfaatkan. Data tersebut mencerminkan bahwa sebenarnya krisis air yang dialami oleh masyarakat Indonesia saat ini bukan karena kekurangan air, melainkan karena kualitas air yang rendah yang disebabkan tata kelola air yang buruk. (Liyana, 2014)

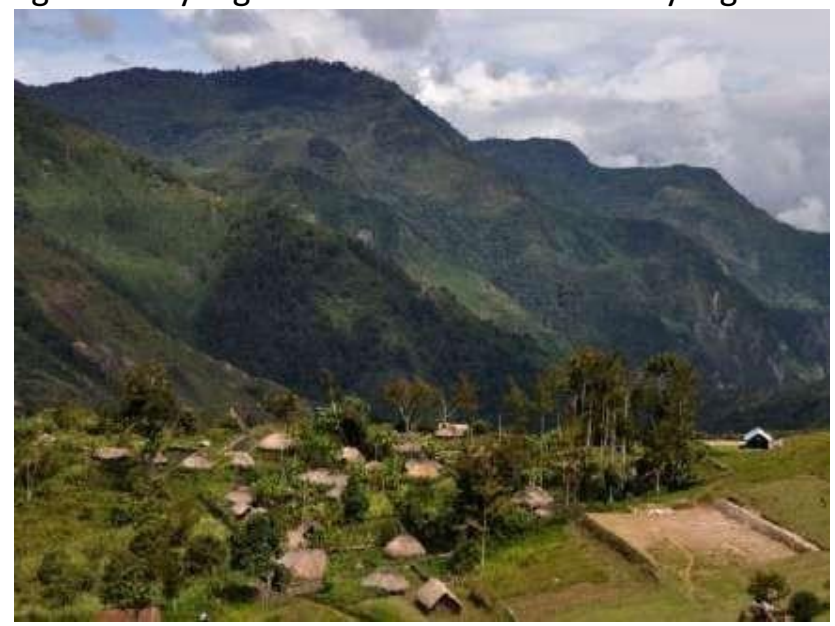

Gambar 2. Alam Papua

Sumber : www.google.com, 2018 
Perubahan iklim juga berpengaruh pada sumber daya air yang ada di seluruh dunia. Pada sisi lain, fenomena pemanasan global menjadikan ekosistem tempat tinggal Suku Asmat berubah. Pegunungan Jayawijaya yang dikenal dengan salju abadinya menjadi berubah. Dimana yang awalnya bersuhu 4-7 derajat akan menjadi 14-17 derajat. Dimana kenaikan suhu tersebut berdampak pada peningkatan drastis kelembaban udara di kawasan tersebut. (Haryanto, 2017)

Fenomena unik di Papua dan khususnya Suku Asmat yang kaya dengan hasil alamnya namun di satu sisi mengalami krisis air bersih. Banyak penyakit di sana yang diakibatkan oleh kondisi air yang buruk karena sebagian masyarakat menggunakan air hujan dan air sungai tanpa diolah terlebih dahulu. Masalah krisis air menjadi permasalahan pokok yang berdampak kepada ekologi alam Suku Asmat. Dimana Suku Asmat sangat bergantung dengan alam mulai dari kebutuhan pangan, MCK, tradisi dan keseniannya.

Budaya hidupnya Suku Asmat hingga saat ini masih tergolong jauh dari peradaban manusia sekarang atau dengan keprimitifannya yang mendewakan atau mensakralkan alam mulai dari kepercayaan, mata pencaharian, pakaian, dan tradisi serta keseniannya yang masih sangat tergantung dengan alam. (Apriyono, 2015)

Namun disisi lain Suku Asmat terdampak dengan masalah global yang sedang terjadi, yang turut merubah alam tempat hidupnya. Mulai dirasakan terjadinya krisis air yang dialami Suku Asmat yang dahulu tidak pernah mereka rasakan. Mungkin di masa mendatang dapat menghilangkan alam rumah nenek moyangnya, padahal Suku Asmat sudah memiliki cara hidupnya sendiri, mulai dari berburu dan meramu yang sangat dekat dengan alam.

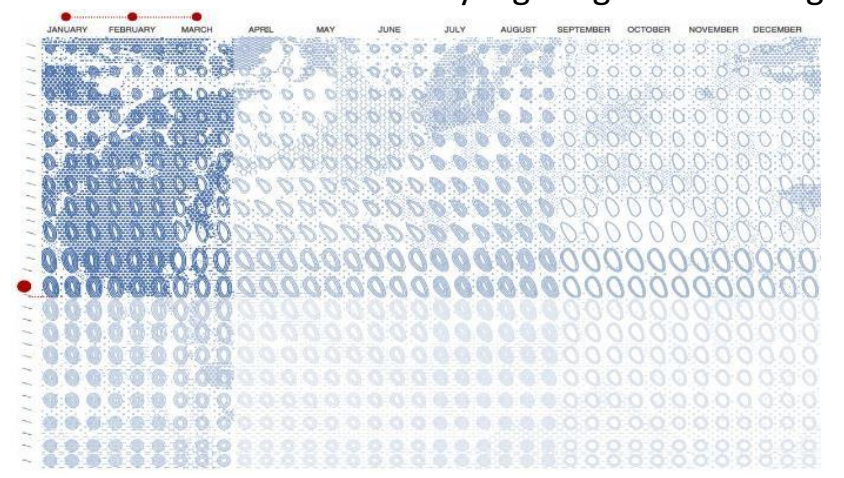

Gambar 3. Data Statistik Curah Hujan Di Papua

Sumber: Dokumentasi Pribadi, 2021

Kabupaten Asmat memiliki iklim tropis basah, dimana memiliki curah hujan dan kelembaban yang tinggi. Curah hujan dalam setahun rata-rata 3.000 - 5.000 milimeter dengan rata-rata 16 hari dalam 1 bulan. Karena dipengaruhi oleh iklim tropis basah, kelembaban rata-rata cukup tinggi di mana antara 78 - 81 persen. Kelembaban dan curah hujan yang tinggi sangat potensial untuk dimanfaatkan sebagai sumber air di masa depan.

\section{Rumusan Permasalahan}

Saat ini adanya permasalahan krisis air bersih yang terjadi pada Suku Asmat menjadi permasalahan mendasar, karena peran air yang sangat besar untuk kegiatan sehari-hari. Di sisi lain Suku Asmat akan terdampak dari pemanasan global yang menyebabkan melelehnya salju abadi di Pegunungan Jayawijaya. Fenomena ini akan berdampak terhadap naiknya kelembaban yang drastis. Selain itu curah hujan yang tinggi serta kelembaban pada dasarnya merupakan uap air yang ada di udara. Berangkat dari hal ini, menjadi awal pertanyaan berikut:

Apakah kelembaban dan hujan dapat menjadi sumber air di masa depan? Bagaimana cara menghasilkannya dan konteksnya dengan Suku Asmat? 


\section{Tujuan}

Proyek ini dibuat untuk tujuan menyelesaikan permasalahan krisis air bersih dan menyikapi fenomena meningkatnya kelembaban yang terjadi pada Suku Asmat di Papua. Proyek ini dapat menjadi jawaban untuk melihat segala masalah dan fenomena yang terjadi menjadi sebuah kesempatan dalam berarsitektur. Penerapan Ecohydrology Architecture, dengan mempelajari karakteristik air untuk menjawab permasalahan dan fenomena yang terjadi, sekaligus menciptakanekologi berhuni baru untukSuku Asmat kedepannya dengan melibatkan alam ke dalam perencanaan. Mengangkat cara hidup Suku Asmat dengan segala tradisi dan keunikan yang ada dan memproyeksikannya di masa depan.

\section{KAJIAN LITERATUR}

Ekologi merupakan cabang ilmu yang fokus mempelajari interaksi antara organisme dengan lingkungannya. Ekologi berasal dari bahasa Yunani, terdiri dari kata oikos yang artinya "habitat" dan kata logos yang artinya "ilmu". Jadi, ekologi dapat diartikan sebagai ilmu yang mempelajari interaksi antar makhluk hidup maupun interaksi antara makhluk hidup dan lingkungannya. Ernst Haeckelmerupakan ahli biologi yang pertama kali memperkenalkan Istilah ekologi. Dalam ekologi, makhluk hidup dipelajari sebagai kesatuan atau merupakan sistem dengan lingkungannya. (Haeckel, 2013)

Ekologi tidak lepas dari kata ekosistem dimana berkaitan dengan komponen penyusunnya yaitu faktor biotik dan faktor abiotik. Faktor biotik adalah makhluk hidup yang terdiri dari manusia, hewan, tumbuhan, dan mikroba, sedangkan faktor abiotik terdiri dari suhu, air, kelembaban, cahaya, dan topografi. Ekologi berhubungan erat dengan tingkatan organisasi makhluk hidup yaitu populasi, komunitas, dan ekosistem yang saling mempengaruhi satu dengan lainnya dan merupakan suatusistem yang menunjukkan satu kesatuan. (Buckhori, 2017)

\section{Parameter Beyond Ecology}

Energy and Emission adalah kemampuan untuk menerapkan zero $\mathrm{CO} 2$ emission dalam pengoperasionalan bangunan dan meminimalisir efek karbon dalam material dan konstruksi.

Adaptation adalah kemampuan untuk melakukan riset dan desain yang berkaitan dengan berbagai dampak, seperti naiknya suhu bumi, naiknya permukaan laut, kekeringan, banjir, kelangkaan pangan, dan perubahan populasi.

Resilience adalah kemampuan untuk membangun kelanjutan "hunian" dan pemulihan cepat setelah kejadian guncangan, bencana alam, gangguan listrik atau iklim.

Sustainable Digital adalah kemampuan untuk melihat data-data lingkungan sebagai Big Data

dalam menentukan taktik dan strategi dalam membangun kualitas spatial.

New Technology adalah kemampuan memanfaatkan teknologi terbaru untuk meningkatkan kualitasdan terapan ruang-konstruksi dan program bangunan

Context adalah kemampuan dalam melihat posisi "tempat" dalam hubungan dengan lingkungan (flora - fauna, biotik - abiotik) dimana sebuah konfigurasi keruangan akan ditempatkan. 


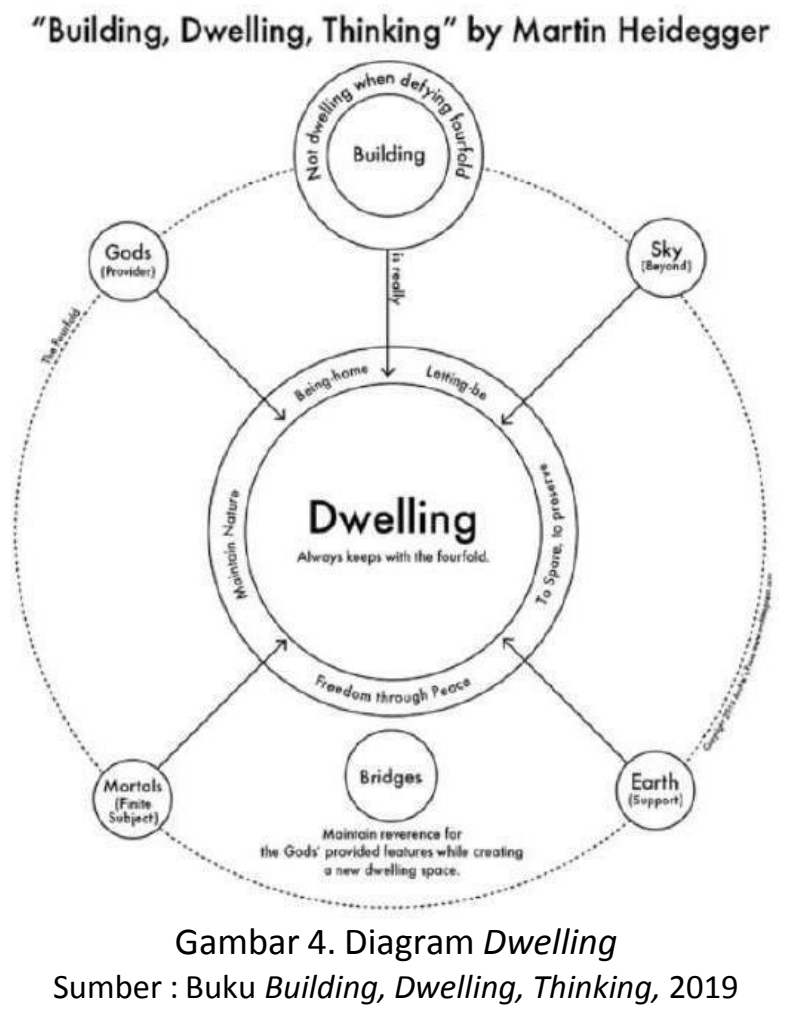

Secara etimologis, kata to dwell berasal dari kata Inggris lama yaitu dwellan yang artinya mengembara, menunda, mendiami, tinggal di suatu tempat lebih lama. Kata dwelling, merupakanbentuk kata benda dari kata kerja to dwell yang memiliki makna kehadiran - human dwelling ataubermakna kehadiran manusia secara spasial di muka bumi.

Salah satu filsuf dunia yang mengupas makna dwelling secara mendalam adalah Martin Heidegger. Dimana menurut Heidegger, kita merasa bertinggal hanya karena hidup dan ada di dalam bangunan. Menurut dia tidak semua bangunan merupakan tempat untuk tinggal. Bangunan untuk menaungi manusia, menempatinya tetapi bukan tempat tinggal atau berhuni.Dia menempati bangunan tetapi bukan tinggal atau berhuni di dalamnya. Jika bangunan hanya sebagai naungan, berarti berhuni lebih jauh bermakna jika ada aktivitas manusia di bawah naungan tersebut. (Heidegger, 1971)

\section{METODE}
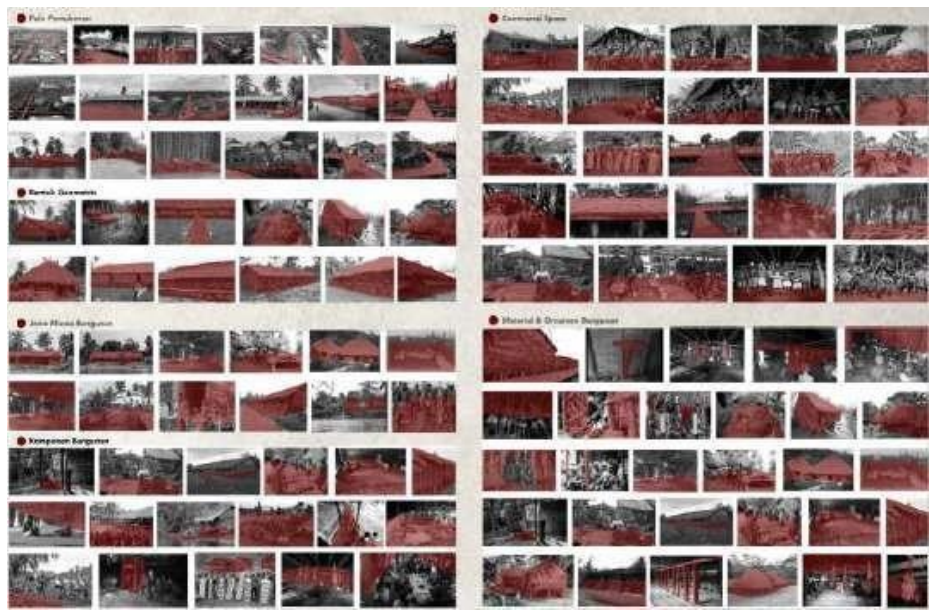

Gambar 5. Tipologi Arsitektur Suku Asmat

Sumber: Dokumentasi Pribadi, 2021 
Tipologi merupakan ilmu atau kegiatan studi untuk mencari jenis dan mengklasifikasi sebuah objek. Dimana harus didasarkan pada beberapa karakteristik terkait agar mampumenjelaskan sebuah bahasa atau adanya pola dalam sebuah fenomena. (Lang, 2005)

Dari studi tipologi yang telah penulis lakukan dapat ditarik beberapa kesimpulandiantaranya, yaitu:

- Pola Pemukiman, didominasi pola pemukiman "grid" dimana tersusun dari polapemukiman yang linear. Dimana diawali dengan pemukiman di sepanjang aliran sungai.

- Bentuk Geometris, didominasi dengan bentuk geometris persegi panjang dan lengkung pada hunian Rumah Tysem (inti). Dimana hunian Suku Asmat didominasi dan berupa hunian deret.

- Jenis Massa Bangunan, massa bangunan yang umum di dalam Suku Asmat adalah Rumah Jew (rumah bujang ,1 unit), Rumah Inti (yang sudah menikah, beberapa unit), dan Pelataran (untuk serbaguna).

- Komponen Bangunan, komponen yang khas dari setiap hunian Suku Asmat adalah tungku api (jumlah menyesuaikan keluarga) selain untuk masak juga digunakan untuk sarana berkumpul dan berdiskusi dengan mengelilinginya.

- Material dan Ornamen, material keseluruhan berasal dari material alam (daun sagu, kayubesi, dan rotan), di dalam rumah banyak ornamen seperti patung, ukiran, tombak, tameng dan anyaman yang diletakan digantung dan dekat dengan tungku api agar awet (kering) dalam penyimpanannya.

Dengan mempertimbangkan studi tipologi tersebut, dapat diketahui desain yang diharapkan di suatu tempat berdasar karakteristik dan kebutuhannya. Sehingga dapat dihindari hal-hal yang tidak sesuai dengan penghuni atau pemakai dari bangunan. Selain pertimbangan di atas, unsurunsur nonverbal dari suatu budaya seperti jenis makanan, gerak tubuh, pakaian, perletakan, bentuk dan susunan ruang dalam rumah dapat mempengaruhi perilaku manusia. (Rapoport, 1982)

\section{DISKUSI DAN HASIL}

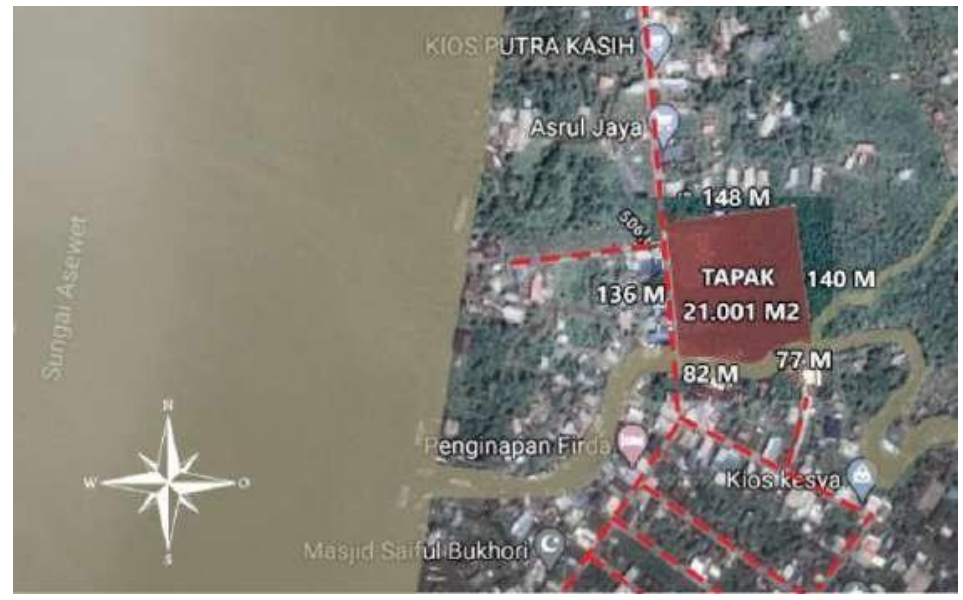

Gambar 6. Pemetaan dan Zonasi Mikro

Sumber : Dokumentasi Pribadi, 2021

Lokasi : Bis Agats, Agats, Kabupaten Asmat, Papua

Luas Tapak : $21.001 \mathrm{M}^{2}$

Kondisi Tapak :

- Tapak merupakan lahan kosong

- Berbatasan langsung dengan sungai

- Berbatasan langsung dengan hutan

- Kondisi sungai berlumpur dan keruh

- Kondisi tanah lembek dan merupakan lahan gambut 


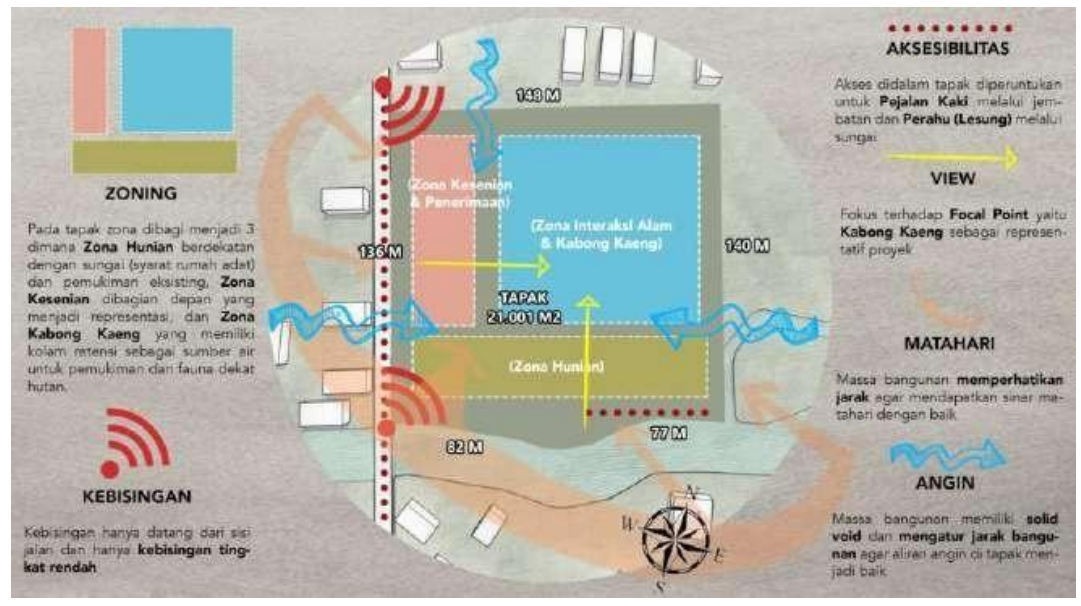

Gambar 7. Analisis Tapak Mikro

Sumber : Dokumentasi Pribadi, 2021

Pada gambar analisis tapak mikro tersebut, penulis memetakan dan menganalisis beberapa aspek atau elemen yang kedepannya digunakan atau diterapkan ke dalam perancangan seperti zoning, kebisingan, aksesibilitas, view, matahari, dan angin. Dimana hasil dari analisis elemen tersebut menjadi hasil perancangan berupa pembagian 3 zona, yaitu zona kesenian, zona hunian, dan zona interaksi alam \& kabong kaeng.

\begin{tabular}{|c|c|c|c|c|}
\hline \multicolumn{2}{|c|}{ Hierarki Fungsi } & \multirow{2}{*}{ Luas / Unit (M2) } & \multirow{2}{*}{ Jumlah } & \multirow{2}{*}{ Total Luasan (M2) } \\
\hline Kelompok Fungsi & Elemen & & & \\
\hline \multirow{2}{*}{ Kabong Kaeng } & Menara Kabong Kaeng & 12 & 6 & 72 \\
\hline & Kabong Kaeng & 42 & 6 & 256 \\
\hline \multirow{4}{*}{ Koloni Jew } & Rumah Tysem & 64 & 10 & 640 \\
\hline & Ruang Pertunjukan & 320 & 1 & 320 \\
\hline & Rumah Jew & 300 & 1 & 300 \\
\hline & Pelataran Budaya & 640 & 1 & 640 \\
\hline \multirow{3}{*}{ Ruma Tunju } & Museum Suku Asmat & 1280 & 1 & 1280 \\
\hline & Galeri Suku Asmat & 1280 & 1 & 1280 \\
\hline & Amphiteater & 640 & 1 & 640 \\
\hline \multirow{3}{*}{ Pono Air } & Penampungan Air & 1280 & 1 & 1280 \\
\hline & Filtrasi Air & 128 & 2 & 128 \\
\hline & Parkir Lesung & 8 & 12 & 96 \\
\hline \multicolumn{4}{|c|}{ Total Luasan Ruang } & 6932 \\
\hline \multicolumn{4}{|c|}{ Estimasi Sirkulasi $20 \%$} & 136 \\
\hline \multicolumn{4}{|c|}{ Estimasi Servis $10 \%$} & 680 \\
\hline \multicolumn{4}{|c|}{ Total Luasan Bangunan } & 7748 \\
\hline
\end{tabular}

Gambar 8. Luasan Program Ruang

Sumber : Dokumentasi Pribadi, 2021

\section{Program Utama:}

\section{Kabong Kaeng (Adaptation)}

Merupakan program utama yang mengolah kelembaban udara menjadi sumber air baru dengan memanfaatkan prinsip evaporasi (penguapan) dan absorbsi (penyerapan), serta water harvesting dari air hujan yang cukup melimpah.

\section{Koloni Jew (Interacted Dwelling)}

Merupakan kompleks hunian Suku Asmat (Rumah Jew) yang telah menjadi lebih adaptif dalam menerima iklim dan perubahan zaman. Berfokus pada skema baru berinteraksi dengan sesama dan alam dengan segala flora dan faunanya.

\section{Pono Air (Resilience)}

Dalam bahasa Indonesia berarti "Penuh A ir" sebagai representasi tempat penampungan air yang terus penuh untuk Suku Asmat dengan harapan tidak pernah kekurangan air bersih kedepannya.

Ruma Tunju (Cultural and Communal Space) 
Dalam bahasa Indonesia berarti "Rumah Pertunjukan" dimana dapat menjadi tempat berkumpul dan bersosialisasi antar sesama Suku Asmat dan orang luar yang berkunjung ke Suku Asmat. Ruma Tunju juga menjadi wadah untuk menunjukkan karya ukir dan pahat Suku Asmat yang mendunia.

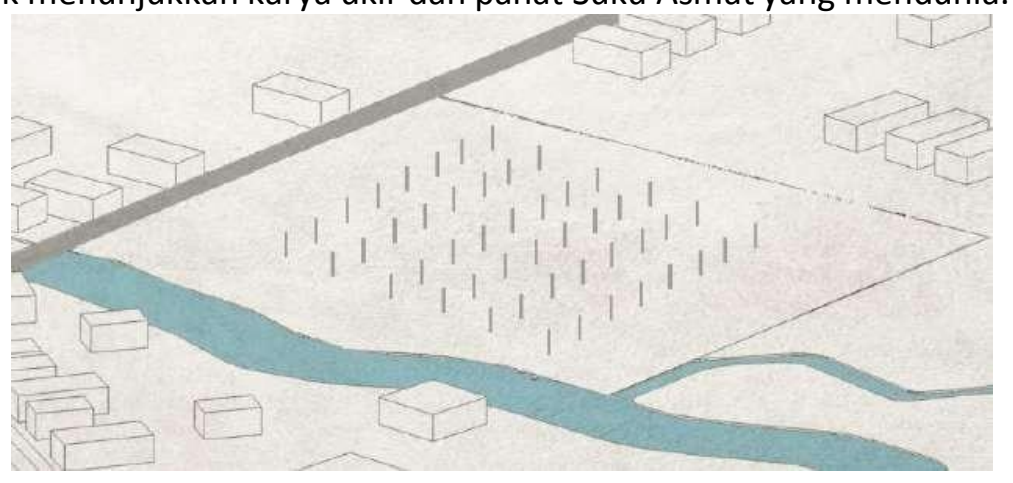

Gambar 9. Menaikkan Tapak

Sumber : Dokumentasi Pribadi, 2021

\section{Menaikkan Tapak}

Membuat dasar bangunan menjadi struktur panggung dan sebagai bentuk adaptasi dari tanah lembek dan berawa, sekaligus bentuk antisipasi dari kenaikan air sungai, panggung juga merupakan ciri khas dariarsitektur Asmat.

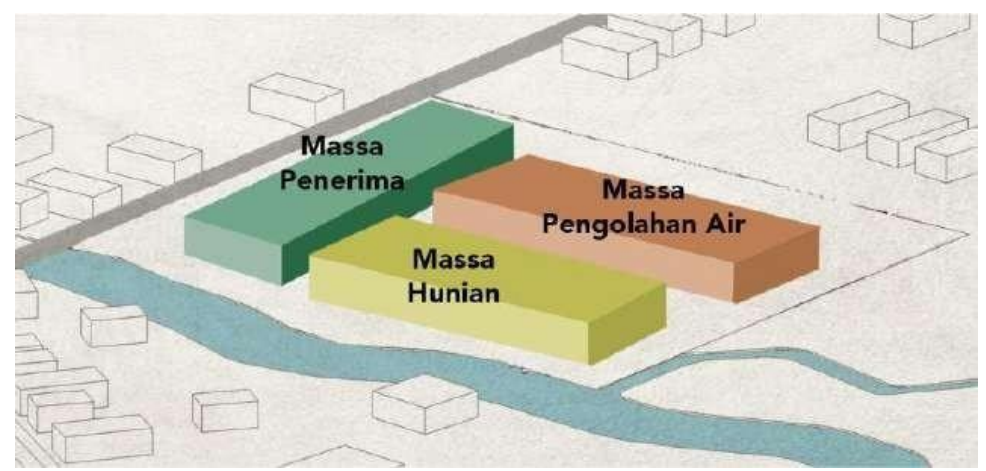

Gambar 10. Zonasi Fungsi

Sumber : Dokumentasi Pribadi, 2021

\section{Zonasi Fungsi}

Membagi massa dengan menyesuaikan fungsi berdasarkan hubungan dengan sekitar dan kepentingan fungsi, massa penerima di bagian depan, hunian di sisi sungai dan pengolahan air yang menyebar di dalam tapak.

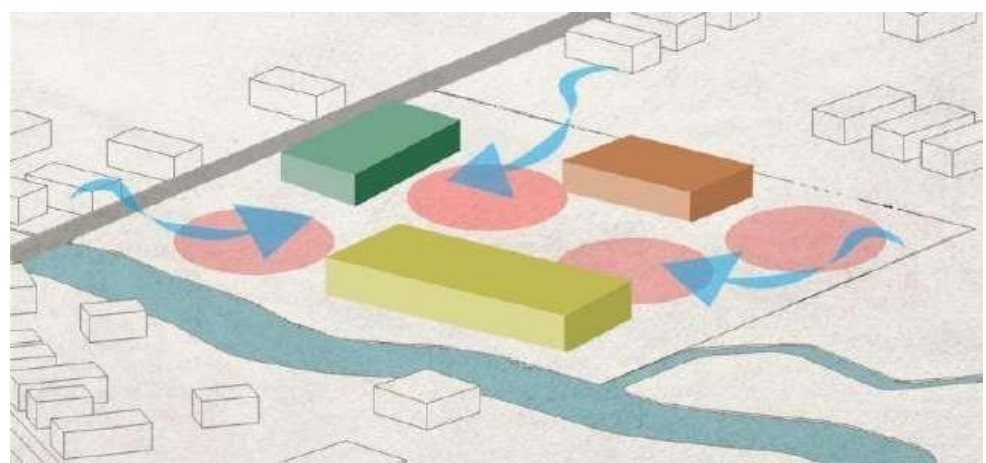

Gambar 11. Spatial Gubahan

Sumber : Dokumentasi Pribadi, 2021

\section{Spatial Gubahan}

Menyiapkan ruang terbuka dan interaksi alam untuk Suku Asmat berkegiatan sehari-hari terutama 
dalam kesenian dan tempat tinggalnya yang menyatu dengan alam serta memberikan pengudaraan, ruang terbuka hijau, view, pencahayaan dan kualitas ruang yang lebih baik.

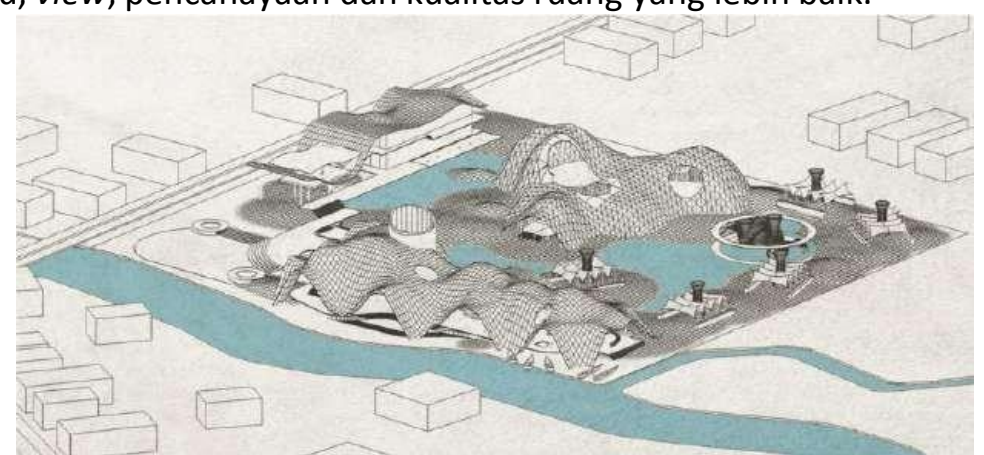

Gambar 12. Pendekatan Desain

Sumber : Dokumentasi Pribadi, 2021

\section{Pendekatan Desain}

Gubahan memiliki karakter Asmat yang merupakan dari hasil studi tipologi hunian Asmat yang berderet dan representasi dari alam di Agats, Papua yang didominasi sungai, rawa, hutan dengan latar belakang Pegunungan Jayawijaya.

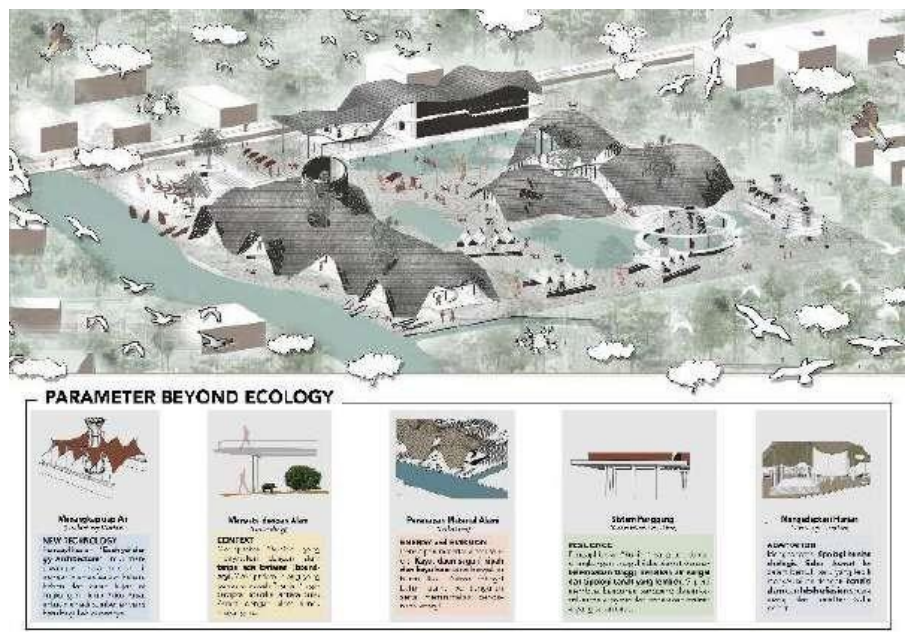

Gambar 13. Parameter Beyond Ecology

Sumber : Dokumentasi Pribadi, 2021

\section{New Technology}

Pengaplikasian "Ecohydrology Architecture" untuk menjawab permasalahan krisis air dengan memanfaatkan kelembaban dan curah hujan di lingkungan hidup Suku Asmat untuk menjadi sumberair yang baru bagi kehidupannya.

\section{Context}

Menciptakan "hunian" yang menyatukan dengan alam tanpa ada batasan (boundary). Menciptakan ruang yang bebas di bawah "hunian" agar tercipta interaksi antara Suku Asmat dengan alam nenek moyangnya.

\section{Energy and Emission}

Penerapan material alami seperti kayu, daun sagu / nipah dan kayu besi yang banyak di hutan Suku Asmat sebagai bahan utama pembangunan serta meminimalisir penggunaan energi.

\section{Resilience}

Pengaplikasian "hunian" yang beradaptasi lingkungan tinggal Suku Asmat dengan kelembaban tinggi, kenaikan air sungai dan tipologi tanah yang lembek. Seperti membuat bangunan panggung dalam 
keseluruhan program dan penerapan material yang tahan cuaca.

\section{Adaptation}

Mengadaptasi tipologi hunian ekologis Suku Asmat ke dalam bentuk baru yang lebih menyesuaikan dengan kondisi alam dan lebih efisien secara ruang dan karakter Suku Asmat.

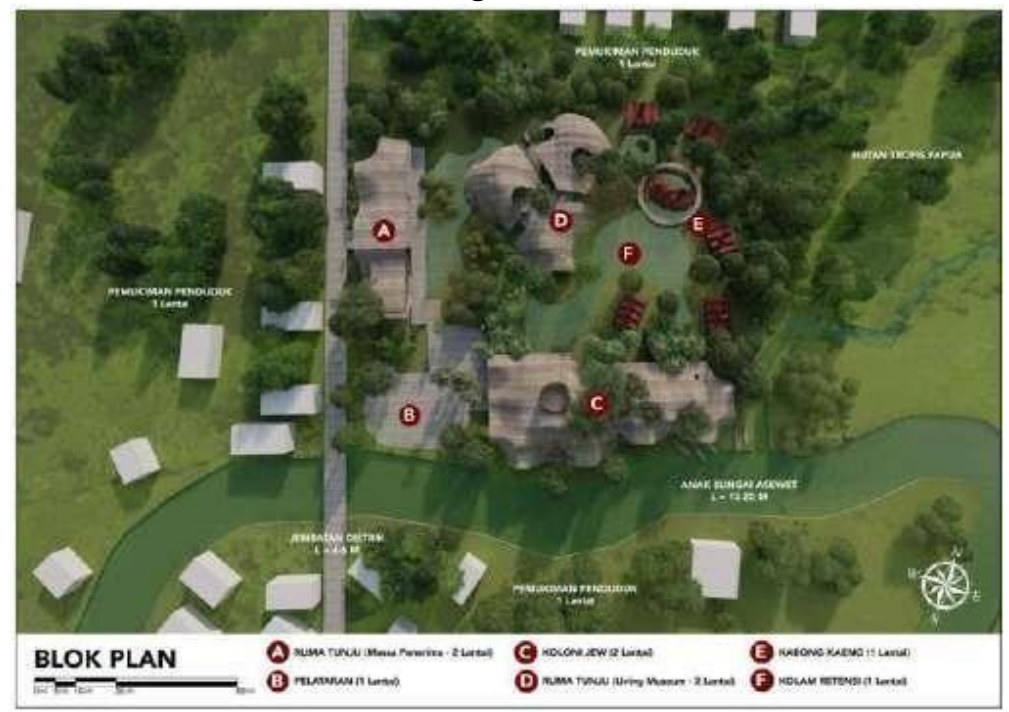

Gambar 14. Blok Plan

Sumber : Dokumentasi Pribadi, 2021

Menyusun kelompok ruang berdasarkan kedekatan hubungan dan aktivitas yang terjadi. Kelompok hunian didekatkan ke sungai karena adanya lesung atau perahu yang menjadi transportasi utama Suku Asmat. Museum di bagian depan sebagai massa penerima atau massa transisi dari dunia luarke kehidupan Suku Asmat. Sedangkan, alat untuk menampung dan mengolah air diletakkan dibagian tengah dan menyebar menyatu dengan alam. Susunan ruang yang terbentuk juga harus dilengkapi bentuk dan orientasi di dalam polanya. (Ching, 2000)

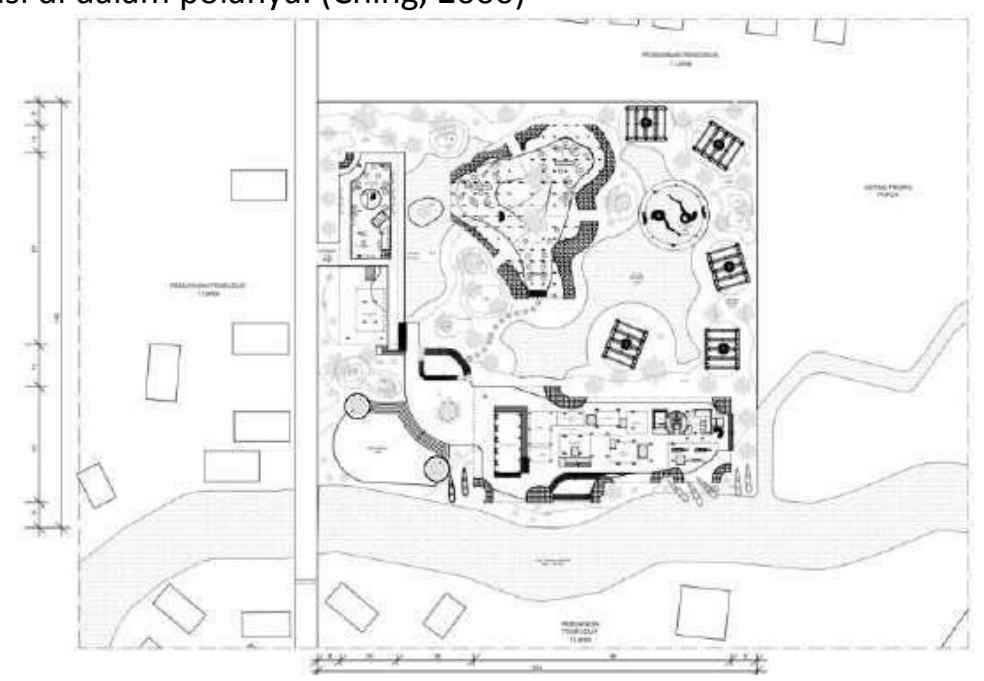

Gambar 15. Denah Lantai Dasar Keseluruhan (Site Plan) Sumber : Dokumentasi Pribadi, 2021

Pada level lantai dasar, proyek ini difokuskan untuk memperkenalkan dan menaungi aktivitas seharihari dan kesenian pahat Suku Asmat. Mulai dari fungsi museum untuk memperkenalkan kebudayaan dan tradisi kepada turis lokal dan mancanegara. Untuk fungsi ruang dibawah hunian juga digunakan sebagai area workshop, mulai dari patung, lesung, dan anyam daun sagu. Pada lantai dasar juga dibuat terbuka dan menyatu dengan alam tanpa adanya batasan dan vegetasi yang dibuat membaur dengan alam sekitar. 


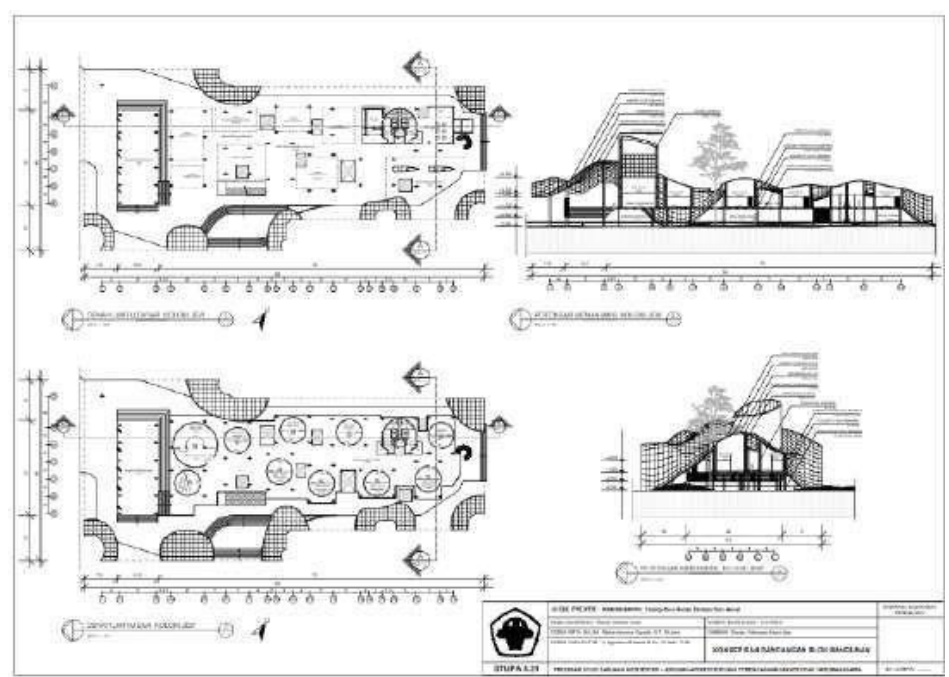

Gambar 16. Denah dan Potongan Koloni Jew Sumber : Dokumentasi Pribadi, 2021

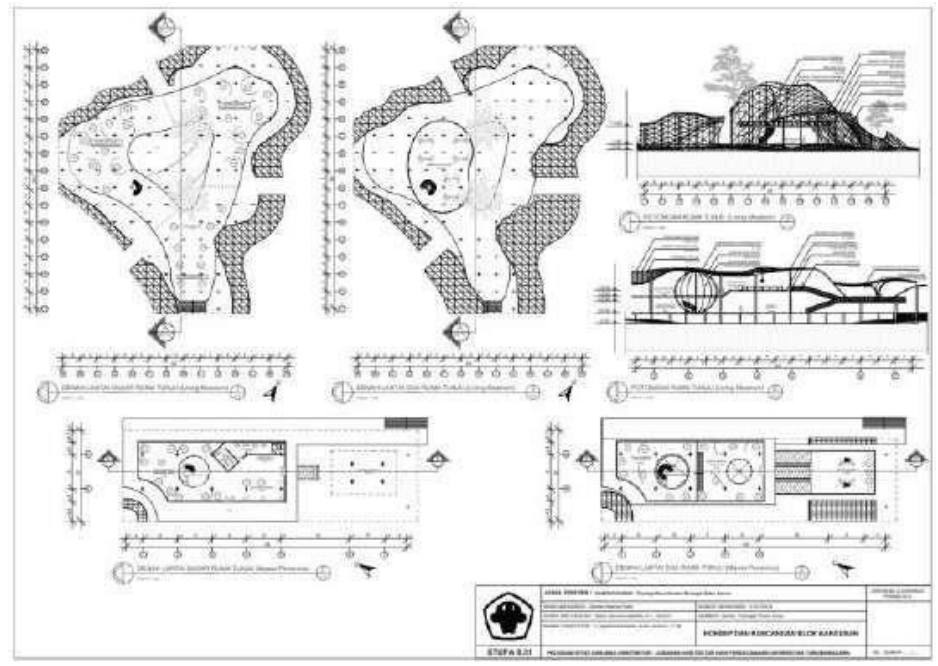

Gambar 17. Denah dan Potongan Ruma Tunju Sumber : Dokumentasi Pribadi, 2021

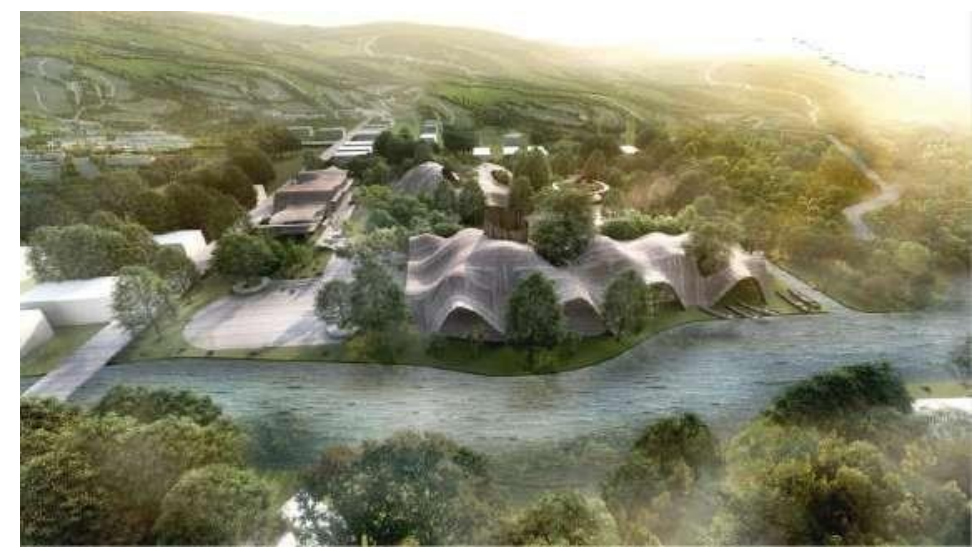

Gambar 18. Visualisasi Render Perspektif Sumber : Dokumentasi Pribadi, 2021 
Proyek berbatasan langsung dengan sungai yang dihubungkan dengan parkiran lesung yang menjadi transportasi utama bagi Suku Asmat. Suasana asri di Agats yang berkabut, dan penuh dengan pepohonan yang dikelilingi sungai dan rawa-rawa dengan latar belakang Pegunungan Jayawijaya. Diharapkan proyek yang mengadaptasi dari kebiasaan dan keseharian Suku Asmat menjadikannya terbiasa dan mempermudah serta memperkuat karakter Suku Asmat yang kuat dengan kesenian terutama karya pahatnya yang mendunia. Pendekatan gaya bangunan dengan bentuk organik, seperti bentuk bangunan yang "dipahat" di tanah papua yang merepresentasikan gunung dan rawa.

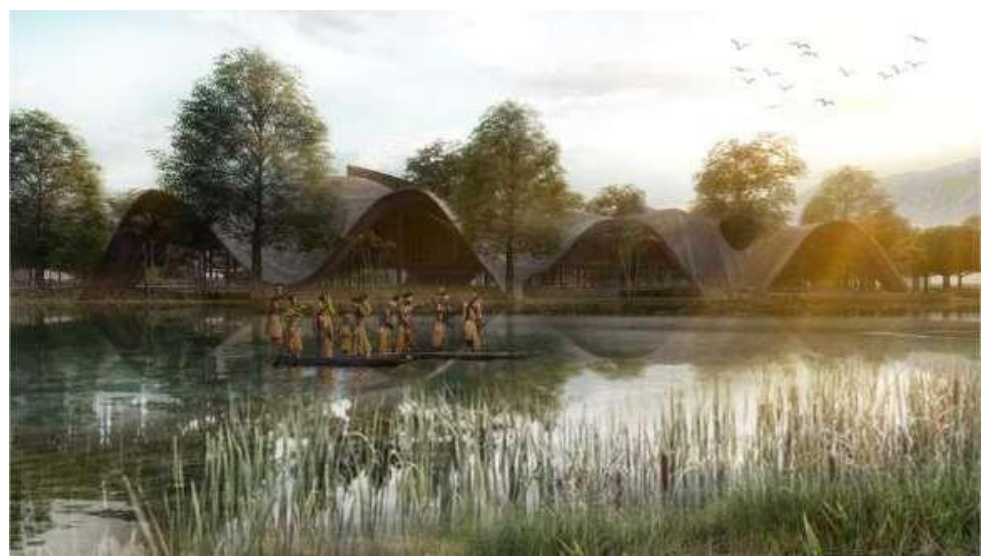

Gambar 19. Visualisasi Eksterior Koloni Jew

Sumber : Dokumentasi Pribadi, 2021

Koloni Jew diadaptasi dari hunian Rumah Tysem yang berderet dan memiliki atap lengkung. Sungai yang menjadi pokok aktivitas dan merupakan elemen penting dalam keseharian suku asmat. Koloni Jew sendiri memiliki ruang komunal di dalamnya yang berfungsi sebagai tempat untuk Suku Asmat berdiskusi dan berkesenian meneruskan tradisi dari leluhur nenek moyangnya. Pada atap juga dibuat bukaan agar menciptakan sirkulasi udara yang baik untuk kehidupan Suku Asmat.

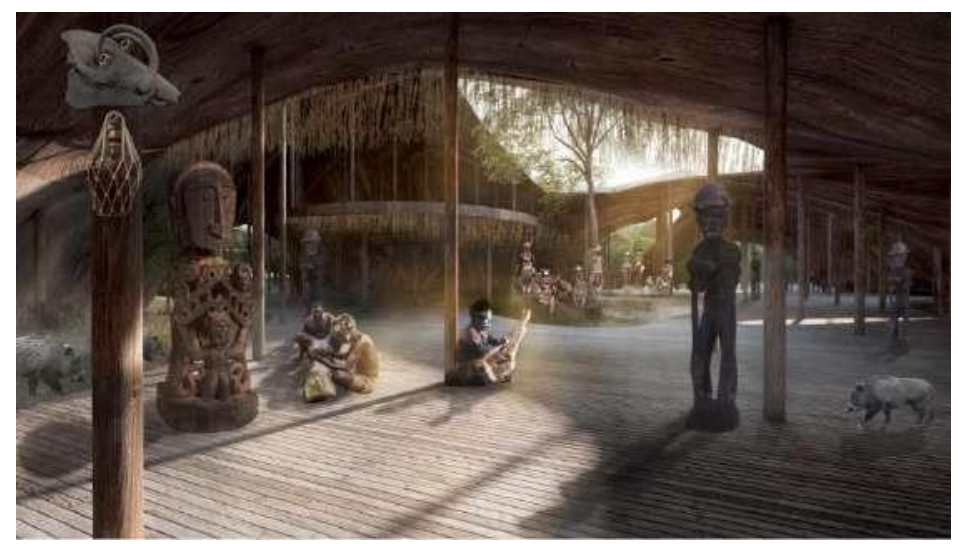

Gambar 20. Visualisasi Interior Ruma Tunju (Living Museum) Sumber : Dokumentasi Pribadi, 2021

Ruma Tunju (Living Museum) menjadi tempat untuk Suku Asmat menunjukkan kepada dunia luar mengenai kualitas karya pahat mereka dimana tidak hanya menjadi tempat pamer tetapi juga workshop pahat. Penerapan material alami yang dominan bertujuan untuk menciptakan suasana yang sesuai dengan alam dan lingkungan asli Suku Asmat. 


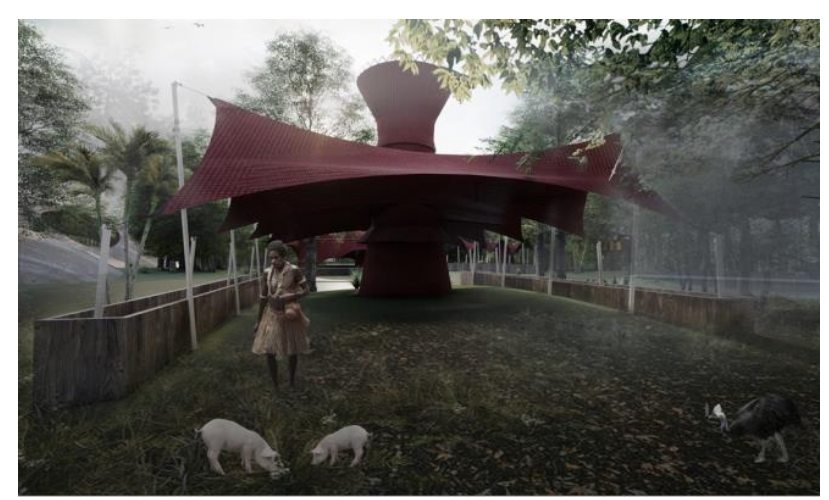

Gambar 21. Visualisasi Kabong Kaeng (Water Harvesting) Sumber : Dokumentasi Pribadi, 2021

Kabong Kaeng menjadi tempat untuk menyelesaikan masalah krisis air bersih yang melanda Suku Asmat. Menerapkan sebuah pemikiran yang sederhana, dengan mempertimbangkan air yang berasal dari curah hujan dan kelembaban yang tinggi, untuk kemudian ditampung ke dalam bak penampungan. Selain bak penampungan, kolam yang terdapat di antara bangunan difungsikan sebagai media untuk menampung air dalam skala besar jika terjadi kepentingan mendesak seperti kemarau panjang. Untuk pengolahan air dilakukan beberapa tahapan, mulai dari penampungan, sedimentasi, filtrasi, pelunakan, chemical addition, deionisasi, dan daerasi.

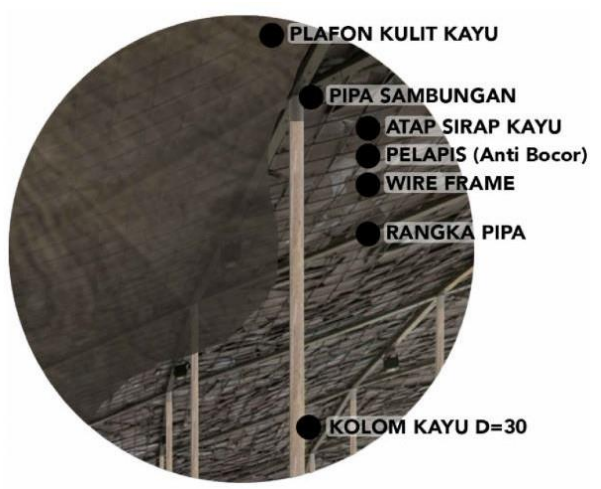

Gambar 22. Penerapan Material dalam Proyek Sumber : Dokumentasi Pribadi, 2021

Proyek ini sebagian besar menerapkan material alami yang masih melimpah di alam Papua, diantaranya adalah penggunaan kayu merbau atau yang biasa dikenal dengan kayu besi. Kayu ini memiliki keunggulan dimana tahan terhadap cuaca alam Suku Asmat yang memiliki curah hujan dan kelembaban yang tinggi. Material kayu ini diterapkan mulai dari pondasi, kolom, balok, panel dinding kayu, plafon, hingga atap sirap kayunya. Material kayu yang ada juga dipadukan dengan besi baja untuk mempercepat proses pembangunan karena menggunakan fabrikasi baja.

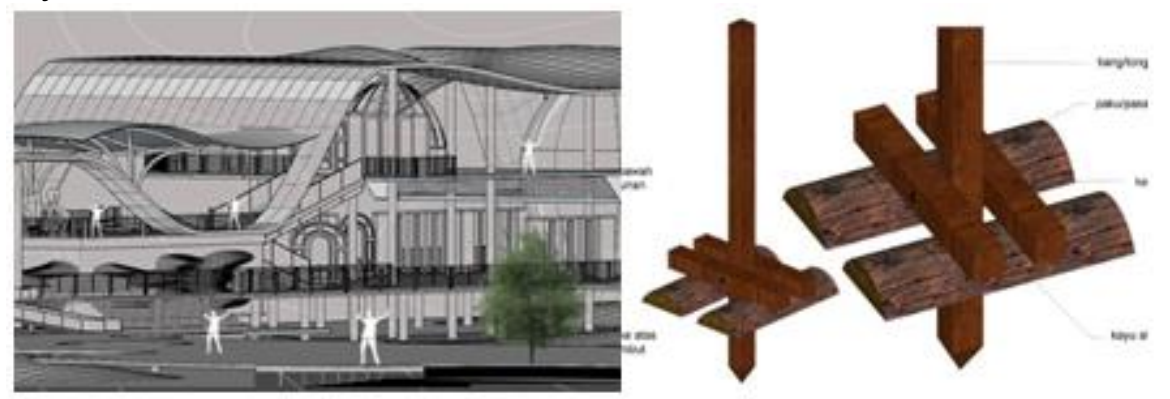

Gambar 23. Penerapan Struktur Bangunan Sumber : Dokumentasi Pribadi, 2021 
Proyek ini menerapkan struktur panggung pada keseluruhan bangunan dengan material kayu merbau atau yang biasa dikenal dengan kayu besi. Struktur panggung juga menjadi dasar dari jembatan papan kayu yang merupakan sirkulasi utama dari kegiatan sehari-hari Suku Asmat. Struktur pondasi menggunakan tiang tongkat dari kayu merbau dimana pondasi ini cocok diterapkan untuk pondasi tanah lembek. Pondasi diteruskan ke kolom kayu dengan diameter 30 cmyang diletakan secara organik atau tersebar, namun tetap memiliki jarak yang terukur. Atap menggunakan kombinasi kayu dengan struktur fabrikasi baja pipa yang dilapisi wiremesh sebagai media untuk memasang atap sirap dan plafon kulit kayu merbau.

\section{KESIMPULAN DAN SARAN}

\section{Kesimpulan}

Pada proyek ini, saya mengangkat isu udara sebagai sumber air masa depan dan water collecting yang dikontekstualkan dengan budaya hidupnya Suku Asmat. Di mana tergolong jauh dari peradaban manusia sekarang atau dengan keprimitifannya yang mendewakan atau mesakralkan alam. Suku Asmat tidak hanya hadir sebagai objek tetapi menjadi karakter dari proyek itu sendiri. Proyek yang berkarakter dengan fokus mengangkat keseharian dan kesenian, terutama dalam materialitas hunian dan karya pahatnya yang mendunia. Proyek ini relevan dengan konteks soal Beyond Ecology dimana mengadaptasi cara hidup dan berhuni Suku Asmat "yang baru" untuk menjawab tantangan zaman. Sehingga, tidak hanya menjawab permasalahan, tetapi juga memiliki karakter lokalitas yang kuat dalam penerapannya.

\section{Saran}

Dalam mendesain proyek ini masih belum sempurna seutuhnya, oleh karena itu masih diperlukan pengembangan lebih lanjut lagi. Adapun saran-saran yang diharapkan dapat membangun proyek ini agar dapat didirikan lebih sempurna. Dimana proyek ini memerlukan waktu lagi untuk dapat memaksimalkan hasil baik dari segi desain keruangan. Proyek ini perlu penyempurnaan dan penelitian lebih lanjut mengenai hubungannya dengan perubahan iklim yang terjadi. Karena proses desain yang terjadi dilatarbelakangi dari informasi dan penelitian yang sebelumnya sudah ada. Begitu juga dengan karakter dan kesesuaian terhadap budaya Asmat itu sendiri.

\section{REFERENSI}

Apriyono, A. Setyo, Sekar M. P. (2015). Kebudayaan Suku Asmat. Surakarta: ISI.

Buckhori, D. (2017). Definisi Ekologi. Diunduh 2 Maret 2021, dari Ipb.ac.id: http://damayanti.staff.ipb.ac.id/files/2012/09/Pendahuluan.pdf.

Ching, F D.K. (tj. Hillarius Hardani). (2000). Arsitektur Bentuk, Ruang dan Tatanan. Jakarta: Erlangga.

Ernst H. (2013). History of Ecological Science. Washington DC: ESA.

Haryanto, I. Januari 5, (2017). BMKG Khawatirkan Puncak Es di Gunung Jayawijaya Meleleh Tahun 2020. Diunduh 2 Maret 2021, dari https://news.detik.com/berita/d-3388887/bmkgkhawatirkan- puncak-es-di-gunung-jayawijaya-meleleh-tahun-2020.

Heidegger, M. (1971). Building Dwelling Thinking. New York: Harper Colophon Books.

Lang, J. (2005). Urban Design, A Typology of Procedures and Products. Oxford: Architectural Press.

Liyana, G. R. (2014). Potensi Air Melimpah Tak Menjamin Indonesia Bebas Krisis Air. Jakarta: Gerry's Note.

Rapoport, A. (1982). The Meaning of Built Environment. Baverly Hills: Sage Publications.

World Resources Institute (WRI). (2019). Kekurangan Air yang Ekstrem. Washington DC: WRI. 